\title{
Distance Learning and the Internet in Respiratory Therapy Education
}

\author{
Sarah M Varekojis PhD RRT, Georgianna G Sergakis PhD RRT, Crystal L Dunlevy EdD RRT, \\ Elbie Foote MSc RRT, and Jill Clutter PhD CHES
}

\begin{abstract}
BACKGROUND: The profession of respiratory therapy (RT) continues to grow both in number, due to population growth and an ever-increasing aging population, and scope of practice, due to both new and expanded roles and responsibilities in divergent areas of clinical practice. Instructional technology, including distance learning, will probably play a key role in training, educating, and assessing RT students to meet the increasing demand for practitioners. OBJECTIVE: To assess current uses of distance learning and opinions concerning the appropriate use of distance education in RT education programs nationwide. METHODS: A 13-item on-line survey was designed to collect information about the frequency of use of various types of distance education typically utilized in RT education programs. The survey was sent to directors of 343 Committee on Accreditation for Respiratory Care accredited programs of RT education that offer entry-level or advanced courses of study. RESULTS: The response rate was 50\% (169 respondents). Fifty-two percent of the respondents indicated that their courses included some form of on-line learning component. Most directors anticipated that the distance composition of their course offerings will remain unchanged or increase in the near future. CONCLUSIONS: Our results indicate that, while distance education plays an important supportive role in RT education, there is still a preference for face-to-face instruction and Internet-facilitated courses among program directors. Program directors continue to view the laboratory and clinical settings as hands-on environments that require instructor supervision in order for students to demonstrate proficiency and critical thinking skills. When used appropriately, distance learning may be an efficient and effective approach to address the many barriers to education faced by the health workforce in general, including budget constraints, overloaded schedules, the need for on-the-job learning opportunities, and lack of access. Key words: distance learning; on-line education; respiratory therapy education. [Respir Care 2011; 56(11):1808-1811. (C) 2011 Daedalus Enterprises]
\end{abstract}

\section{Introduction}

The profession of respiratory therapy (RT) continues to grow both in number, due to population growth and an ever-increasing aging population, and scope of practice,

\footnotetext{
The authors are affiliated with the School of Allied Medical Professions, The Ohio State University, Columbus, Ohio.

Dr Varekojis presented a version of this paper at the 55th International Respiratory Congress of the American Association for Respiratory Care, held December 5-8, 2009, in San Antonio, Texas.

The authors have disclosed no conflicts of interest.

Supplementary material related to this paper is available at http:// www.rcjournal.com.
}

due to both new and expanded roles and responsibilities in divergent areas of clinical practice. The United States Department of Labor's Bureau of Labor Statistics reported that respiratory therapists held nearly 106,000 jobs in 2008 , about $81 \%$ of which were in hospitals in departments of respiratory care, anesthesiology, or pulmonary medicine. Most of the remaining jobs were in offices of physicians or other health practitioners, consumer-goods rental firms that supply respiratory equipment for home use, nursing care

\footnotetext{
Correspondence: Sarah M Varekojis PhD RRT, School of Allied Medical Professions, The Ohio State University, $453 \mathrm{~W}$ Tenth Avenue, Atwell Hall, Columbus OH 43210. E-mail: varekojis.16@osu.edu.
}

DOI: $10.4187 /$ respcare. 01197 
facilities, employment services, and home healthcare services. The Bureau of Labor Statistics projected that employment of respiratory therapists will increase by $21 \%$ from 2008 to 2018, much faster than the average for all occupations. The increasing demand is expected to come from substantial growth in the middle-aged and elderly population as well as the expanding role of respiratory therapists in case management, disease prevention, emergency care, and the early detection of pulmonary disorders. ${ }^{1}$

Instructional technology, including distance learning, will probably play a key role in training, educating, and assessing RT students to meet the increasing demand for practitioners. Examples of currently utilized on-line educational offerings include support for classroom instruction, continuing education, and board examination review. While on-line education is commonly used in RT programs, few descriptive or comparative studies have been published about its scope or effectiveness.

In 2004, Hopper proposed that RT is an "excellent match" for on-line support of academic courses, but not suitable to be delivered entirely via distance education. ${ }^{2}$ A 2005 national survey of academic RT program directors reported that the majority of respondents believed distance education to be a "critical long-term strategy" for RT education programs. ${ }^{3}$ A similar survey of both RT program directors and hospital managers reported that $61 \%$ of programs delivered at least one course that included an online component. ${ }^{4}$ While the managers agreed that on-line education was appropriate for continuing education, one third of them would not hire a therapist who was trained entirely through distance learning. Neither the managers nor the educators believed that on-line courses should be used exclusively to train respiratory therapists, and they did not consider distance learning to be a comparable substitute for classroom experience. ${ }^{4}$ Hopper et al concluded that, based on survey results, on-line learning is suitable only as an adjunct to classroom and laboratory instruction.

Other healthcare professions have used distance learning to provide instruction to their students, with positive outcomes. A study of third-year osteopathic medical students who participated in a Web-based interactive instructional module reported that the on-line module enhanced their overall learning experience, although they still preferred classroom lecture. ${ }^{5}$ A Wichita State University study that compared student satisfaction and learning outcomes between classroom and on-line versions of the same allied health pharmacology course reported that, while satisfaction scores were significantly higher for the classroom students with regard to instructor rapport, peer interaction, and self-perceived knowledge gains, both groups' scores were generally high $(>4.0 / 5.0)$. On-line and classroom courses had similar withdrawal rates and exam scores. ${ }^{6}$ Another study examined differences in academic performance between on-line and on-campus programs in clinical laboratory science, nuclear medicine, and healthinformation administration. In terms of their grade point averages, the on-line and on-campus students were indistinguishable, but the on-campus groups scored significantly higher on certification examinations. ${ }^{7}$

The purpose of this study was to assess current uses of distance learning and opinions concerning the appropriate use of distance education in RT education programs nationwide.

\section{Methods}

We designed a 13-item on-line survey (see the supplementary materials at http://www.rcjournal.com) about the frequency of use of various types of distance education typically utilized in RT education programs. The survey's content was based upon previous research, specifically the identification of advantages of and barriers to the implementation of distance learning in RT education programs. A panel of content experts, which included RT program faculty, directors of other allied health programs, and a statistician, reviewed the instrument for clarity and face validity. The survey was sent to the directors of $343 \mathrm{Com}-$ mittee on Accreditation for Respiratory Care accredited RT education programs that offer entry-level or advanced courses of study.

The survey was administered via a survey Web site (http://try.surveymonkey.com). The directors were sent 2 e-mail reminders, and were considered nonrespondents if they failed to respond after the second e-mail. The responses were analyzed with descriptive statistics.

\section{Results}

The response rate was 50\% (169 respondents), and 76\% of the respondents were program directors of advancedlevel associate-degree programs. The average enrollment of programs was 58.5 (range 7-110). Fifty-two percent of the respondents indicated that their courses included some form of on-line learning component. Of those, $32 \%$ of program courses were exclusively on-line (defined as no face-to-face contact), 34\% were blended or hybrid courses (defined as "a substantial portion delivered on-line"), 14\% were internet-facilitated courses (defined as essentially face-to-face courses), and $20 \%$ were exclusively face-toface. The majority of courses that were offered either exclusively on-line or included an on-line component were didactic only (58\%), whereas the most common type of course offered as face-to-face was clinical in nature (62\%). Most directors anticipated that the distance composition of their course offerings will remain unchanged $(50-58 \%)$ or increase (37-47\%) in the near future, whereas the number of face-to-face courses is expected to decline (37\%). Only 
Table 1. Program Directors' Perceived Advantages of Using the Internet in Respiratory Therapy Education $(n=169)$

\begin{tabular}{lc}
\hline \hline \multicolumn{1}{c}{ Advantage } & $\%$ \\
\hline Flexibility & 14 \\
Accessibility & 12 \\
Active learning & 25 \\
Convenience & 19 \\
Provide enhanced resources students & 30 \\
\hline
\end{tabular}

Table 2. Program Directors' Perceived Barriers of Using the Internet in Respiratory Therapy Education $(n=169)$

\begin{tabular}{lr}
\hline \hline \multicolumn{1}{c}{ Barrier } & $\%$ \\
\hline $\begin{array}{l}\text { Difficulty in adapting on-line education to } \\
\quad \text { different learning styles }\end{array}$ & 9 \\
Lack of classroom experience & 9 \\
Additional time and effort required for & 32 \\
$\quad$ implementation and maintenance & 6 \\
Lack of preparation or resources & 28 \\
Inability to offer quality laboratory & \\
$\quad$ experiences & 16 \\
Security issues &
\end{tabular}

$3 \%$ of respondents expected face-to-face course offerings to increase. Respondents reported that they use the Internet to provide course materials, clinical simulations, preparation activities, and supplemental resources for students, to post grades, to allow students to submit assignments, and to document clinical activities and evaluations.

Table 1 indicates the RT program directors' perceived advantages of distance learning and the reported frequency of each. The most common advantage cited was the capacity to enhance the resources available to students. Table 2 indicates the frequency of perceived barriers to distance education. These included the inability to offer comparable laboratory experiences and the time-intensive aspect of implementation and maintenance of an on-line course.

Seventy-five percent of respondents reported that they believed the outcomes (defined as exam scores and course grades) of Internet courses to be the same as or better than those of face-to-face courses. They also reported that students were most engaged and actively involved in Internet-facilitated courses.

\section{Discussion}

Our survey responses support Hopper's 2004 and 2007 conclusions that RT curricula could include on-line components but that it should not be delivered entirely online. ${ }^{2,4}$ The 2007 survey reported that $61 \%$ of RT programs offered at least one course that included an on-line com- ponent, compared to $52 \%$ of programs included in the present study. Hopper's 2007 study reported that neither managers nor educators believed that distance learning was comparable to classroom or laboratory experience. ${ }^{4}$ This is in stark contrast to our survey finding that $75 \%$ of program directors perceived no difference in outcomes (exam scores and final course grades) between on-line and classroom-based courses. The studies of differences in grade point averages and exam scores between on-line and classroom versions of the same course material in osteopathic medicine, clinical laboratory science, nuclear medicine, and health-information systems support our findings. ${ }^{5-7}$

Our results indicate that, while distance education plays an important supportive role in RT education, program directors still prefer face-to-face instruction and Internetfacilitated courses. Most RT programs currently use the Internet to supplement their courses and/or as a means to document student performance. Program directors continue to view the laboratory and clinical settings as hands-on environments that require instructor supervision in order for students to demonstrate proficiency and critical thinking skills.

Our findings have important implications for the future of RT education. Because the majority of the program directors perceived no difference in outcomes between online and classroom-based instruction, effective strategies for administering quality on-line courses should be developed, disseminated, and evaluated. In an era of budget cuts and healthcare reform, in which RT faculty are charged with increasing the number of graduates from their programs, distance learning may prove to be an efficient means of meeting the increasing demand for respiratory therapists without increasing laboratory space and clinical sites, through the efficient delivery of appropriate content.

Our study did not gather information about specific course components that were included in Internet-facilitated or blended/hybrid courses, nor did we compare distance education between associate and baccalaureate degree programs. Future studies aimed at gaining a more comprehensive understanding of specific types or components of courses that might be best suited to online learning are needed.

\section{Conclusions}

RT education and workforce planning need a unified strategy in order to create quality educational approaches that will produce sufficient numbers of therapists to meet future national healthcare needs. Distance learning may be an efficient and effective approach for delivering appropriate content while addressing the many barriers to education faced by the health workforce in general, including budget constraints, overloaded schedules, the need for on- 


\section{Distance LEARNing AND THE INTERNET IN RESPIRATORY THERAPy EDUCATION}

the-job learning opportunities, and lack of access (particularly in rural areas).

\section{REFERENCES}

1. US Department of Labor, Bureau of Labor Statistics. Occupational outlook handbook, 2010-11 edition: respiratory therapists. http:// www.bls.gov/oco/ocos321.htm. Accessed September 7, 2011.

2. Hopper KB. Education, teleconference, and distance learning in respiratory care. Respir Care 2004;49(9):1061-1062.

3. Boone EL, Rye KJ. Distance education in respiratory care. Respir Care Clin N Am 2005;11(3):461-475.
4. Hopper KB, Johns CL. Educational technology integration and distance learning in respiratory care: practices and attitudes. Respir Care 2007;52(11):1510-1524.

5. Peska DN, Lewis KO. Uniform instruction using web-based, asynchronous technology in a geographically distributed clinical clerkship: analysis of osteopathic medical student participation and satisfaction. J Am Osteopath Assoc 2010;110(3):135-142.

6. Hale LS, Mirakian EA, Day DB. Online vs classroom instruction: student satisfaction and learning outcomes in an undergraduate allied health pharmacology course. J Allied Health 2009;38(2):e36-e42.

7. Russell BL, Tekleselassie A, Turnbull D, Arthur L, Burnham J. A comparison in academic performance between distance and oncampus students in allied healthcare education. J Allied Health 2008; 37(1):e1-e21. 